Erratum

\title{
Erratum: Sheng, J. Effect of Uncertainties in Estimated Carbon Reduction from Deforestation and Forest Degradation on Required Incentive Payments in Developing Countries. Sustainability 2017, 9, 1608
}

\author{
Jichuan Sheng ${ }^{1,2}$ (D) \\ 1 Institute for History of Science and Technology, Nanjing University of Information Science \& Technology, \\ 219 Ningliu Road, Nanjing 210044, China; jsheng@nuist.edu.cn \\ 2 School of Economics and Management, Nanjing University of Information Science \& Technology, \\ 219 Ningliu Road, Nanjing 210044, China
}

Received: 19 August 2019; Accepted: 21 August 2019; Published: 29 August 2019

check for updates

The authors would like to make the following corrections about the published paper [1]. The changes are as follows:

(1) Replacing the sentence in "Section Abstract in page 1":

Data from six tropical developing countries is used, including Nigeria, Honduras, Indonesia, Kampuchea, Garner, and Brazil.

with

Data from six tropical developing countries are used, including Nigeria, Honduras, Indonesia, Cambodia, Ghana, and Brazil.

(2) Replacing the sentence in "Section 2.2. Simulation Study in page 5":

Following Plugge, Baldauf and Köhl [30], this paper selects six tropical developing countries with different carbon stock variability to examine the effects of estimated uncertainties: Nigeria, Honduras, Indonesia, Kampuchea, Garner, and Brazil.

with

Following Plugge, Baldauf and Köhl [30], this paper selects the following six tropical developing countries with different carbon stock variability to examine the effects of estimated uncertainties: Nigeria, Honduras, Indonesia, Cambodia, Ghana, and Brazil.

The authors and the Editorial Office would like to apologize for any inconvenience caused to the readers by these changes. The change does not affect the scientific results. The manuscript will be updated, and the original will remain online on the article webpage.

\section{Reference}

1. Sheng, J. Effect of Uncertainties in Estimated Carbon Reduction from Deforestation and Forest Degradation on Required Incentive Payments in Developing Countries. Sustainability 2017, 9, 1608. [CrossRef] 